\title{
Sexual Diversity and Homophobia in Health Care Services: Perceptions of Homosexual and Bisexual Population in the Cross-Cultural Theory
}

\author{
Grayce Alencar Albuquerque ${ }^{*}$, Glauberto da Silva Quirino1, \\ Francisco Winter dos Santos Figueiredo², Laércio da Silva Paiva², Luiz Carlos de Abreu², \\ Vitor Engrácia Valenti ${ }^{3}$, Vânia Barbosa do Nascimento ${ }^{2}$, Erika da Silva Maciel $^{4}$, \\ Fernando Rodrigues Peixoto Quaresma², Fernando Adami ${ }^{2}$ \\ ${ }^{1}$ Regional University of Cariri, Ceará, Brazil \\ ${ }^{2}$ School of Medicine of ABC, São Paulo, Brazil \\ ${ }^{3}$ Paulista State University, Campus of Marilia, São Paulo, Brazil \\ ${ }^{4}$ University Center Lutheran of Palmas CEULP-ULBRA, Tocantins, Brazil \\ Email: "geycyenf.ga@gmail.com, glaubertoce@hotmail.com,winterfigueiredo@gmail.com, \\ fisioterapeutalaerciopaiva@hotmail.com,cdh.fsp@gmail.com, vitor.valenti@gmail.com, \\ vaniabn@uol.com.br, erikasmaciel@gmail.com, ferodriguesto@gmail.com, adamifernando@uol.com.br
}

Received 6 May 2016; accepted 10 June 2016; published 13 June 2016

Copyright (C) 2016 by authors and Scientific Research Publishing Inc.

This work is licensed under the Creative Commons Attribution International License (CC BY).

http://creativecommons.org/licenses/by/4.0/

(c) (i) Open Access

\section{Abstract}

The provision of care by health professionals seems to be related to cultural patterns in which these workers are inserted. The relationship between culture and care becomes a challenge for the provision of health care to homosexual and bisexual population. Thus, this study aimed to identify the perception of Gays, Lesbians, Bisexuals and Transgenders in relation to the care received from health professionals, in the light of Cross-Cultural Theory. This is a qualitative, ethnographic study, conducted with $\mathbf{3 0}$ members of sexual minorities in Juazeiro do Norte, Brazil. The data analysis lead to the elaboration of five categories based on of the Theory of Cultural Care Diversity and Universality. The participants emphasized the constant violation of their rights to universal and equitable access to the National Health System, stating that they have suffered from prejudice and exclusion, as result of a heteronormative culture. They highlighted that homophobia and dehumanization of care have a strong relation to sexual orientation. The transvestites are the most prone to humiliation and pejorative attitudes of professionals and such condition is a barrier to accessing services.

*Corresponding author.

How to cite this paper: Albuquerque, G.A., et al. (2016) Sexual Diversity and Homophobia in Health Care Services: Perceptions of Homosexual and Bisexual Population in the Cross-Cultural Theory. Open Journal of Nursing, 6, 470-482.

http://dx.doi.org/10.4236/ojn.2016.66049 


\section{Keywords}

\section{Health Care, Health Disparities, Discrimination, Homophobia, Theory}

\section{Introduction}

The Lesbian, Gay, Bisexual and Transgender (LGBT) population, due to the inadequacy between gender identity and biological sex, has their basic human rights attacked, among them, the right to health, and they are often in a vulnerable situation [1].

Given this reality, some countries, such as Brazil, through its health system (National Health System-SUS) by establishing the National Policy of Comprehensive Health to GLBT in 2008, recognize that sexual identity and gender identity are constituents of a multifaceted process of discrimination and social exclusion, from which vulnerability factors derive, such as violation of the right to health, dignity, non-discrimination, autonomy and free development [2].

The health vulnerability observed in LGBT seems to be a result of the historical relationship between health and sexual diversity, which remains marked by pathological processes, stigmatization, oppression, neglect and social exclusion [3]. As a result of this situation, some obstacles to organization and effectiveness of health care to the LGBT group arise, ranging from difficulties in communication between professionals and patients to embarrassing attitudes, prejudice and discrimination by health workers toward sexual minorities [3] [4].

It is estimated that prejudice against the LGBT population is the result of cultural and moral standards, beliefs, values and myths that reinforce discriminatory and stereotypical attitudes towards this group [5] [6], since heterosexual conduct is presumed to be normative, correct and moral in society, in response to gender configurations which enhance standard models of masculinity and femininity that must be accepted and followed by men and women socially [7]. This condition can result in gaps in health care provided to LGBT against the heteronormative cultural context in which health professionals are inserted, resulting in provision of inconsistent and unsatisfactory care [8] [9].

Due to this scenario, when sexual minorities seek health services and perhaps suffer discrimination by health professionals, there may be reduction of search for care. Misconduct of health workers may include constraints, prejudiced connotations or even verbal abuse. Such practices and attitudes can be characterized as situations of (sometimes silent) violence that contribute to the reduction of health care to LGBT population [10] [11]. In this sense, it is understood that the heteronormative culture can impose barriers that hinder sexual minorities to access health services.

\section{Theoretical Foundation: Cultural Care}

Care, as a cultural practice, considers behaviors, values and beliefs of individuals who care and who receive care [12]. The "cultural care" figure as a determinant of care between professionals and users, that is, as a health condition [13].

It is likely that some health professionals find difficult to conciliate their cultural beliefs with their care practices [14]. In this sense, cultural issues arising from the standardization of heterosexuality can influence subjectively the care of health professionals to the LGBT population. Some health professionals may be influenced by standardization of heterosexuality that permeates the culture, and the prejudice suffered by the LGBT population can constitute a barrier for them to access health services.

Thus, the (re) knowledge of the sexual orientation of the user may appear to be a bias of care practices. Although professional training in health is permeated by the doctrinal principles that guide the SUS (universality, fairness and integrity), some professionals adopt prejudiced and discriminatory behavior, often permeated by moral and cultural values that consider heterosexuality as universal standard. Thus, the relationship between culture and care practices can be analyzed taking into account the principles of the Theory of Cultural Care Diversity and Universality.

This theory, known as the cross-cultural theory, was proposed by Madeleine Leininger in 1985 as a basis to nursing care [15]. However, it can be generalized to health care provided by other professionals.

The universe of health care is intrinsically linked to cultural factors that interrelate closely with the health- 
disease process [15]. Thus, from the perspective of the cross-cultural theory, it is interesting to analyze how the culture of health professionals, as subjects of care, interferes with the care provided to LGBT group.

The cross-cultural theory has five concepts that should be discussed: 1) culture, 2) worldview, 3) environmental context, 4) care, and 5) health [16].

According to this theory, culture comprises patterns of acquired behaviors and shared values transmitted from generation to generation. Worldview corresponds to how people look and observe the world, building a frame or attitude about this value, cultural beliefs and their lives. The environmental context is the totality of knowledge, situation or particular experience that gives meaning to human experiences, added to social interactions, physical, emotional and cultural dimensions. Finally, care and health are interrelated, since health is a state of well-being, which is culturally defined, and care (in this case, health), is also defined by culture, based on values, beliefs and standardized ways of life, that are learned subjectively and objectively [15] [16].

Certainly, considering the complexity of culture, the stereotypes produced towards the LGBT group impose difficulties to individualized care and cultural practices reinforce messages of discrimination [17].

Although the influence on standards of care due to a sexist and homophobic culture and worldview that are centered on gender binary and heteronormativity may be considered as constraints in health-disease process of sexual minorities-they are little valued and studied. The need to contextualize the relationship between culture and health professional practices should focus on certain groups, such as LGBT, in order to minimize and/or avoid biased and discriminatory attitudes during assistance. Thus, this study aimed to identify the perceptions of LGBT population as the care received by health services in the light of Cross-Cultural Theory.

\section{Method}

An exploratory and qualitative research study was used to analyze how a group of LGBT perceives the care received by health professionals while using their services.

This qualitative study was carried out in the town of Juazeiro, state of Ceara, Brazil, in 2013, through an ethnographic approach. Some concepts guide the ethnographic work, among these, the culture. Culture is defined as a set of knowledge, beliefs and ideas acquired and used by a particular group of people to interpret experience and generate behavior [18]. Still Leininger [15] defines ethnography as a systematic process to observe, describe, describe, document and analyze the lifestyle or specific patterns of a culture or subculture to learn how this is performed and interfere environments and ways of life. Ethnography means the description of a system of cultural meanings of a particular group, in order to understand another way of life, but the informant's point of view. Fieldwork, then, includes the disciplined study of what the world is, how people have learned to see, hear, speak, think and act in different ways.

In this sense, based on the culture in which health professionals are inserted, this study sought to obtain the perceptions of the group on the care received from health professionals through the application of interviews with LGBT members, aiming to interpret and analyze them.

\subsection{Setting and Sample}

The study population consisted of individuals of the LGBT group recruited by the snowball technique (chain of referrals) [19] and who met the inclusion criteria: i) being older than 18 years old, ii) having socially came out about their sexual preferences and iii) being people who had undergone health care treatment.

The director of the association Support Group for Free Sexual Orientation of Cariri (GALOSC) was the key informant, who promptly provided association members phone contact numbers, which enabled us to invite them to participate in the study.

Members, contacted by telephone, were asked about the inclusion criteria and received brief explanation of the purpose of research. For those who agreed to participate in the study, there was a scheduling of a meeting date according to participants' availability for data collection. Interviews were conducted in participants' houses. That way, thirty LGBT members participated in the research, after identifying the theoretical saturation point, which is defined as the speeches of the study participants begin to repeat.

\subsection{Data Collection}

Data collection occurred from May to July 2013, mostly in study subjects' homes. A semi-structured interview 
was used to collect data, and there was authorization to use a recorder. Participants were identified by sexual orientation and then by age in order to guarantee the confidentiality of the information.

The interview, with a total of 15 questions, involved questions about therapeutic itineraries and treatment received in health services: i) For you what is health? ii) How do you see the health of Brazilians? Tell me a little about it. iii) How realizes the health of LGBT members? Because? iv) What do you think of public policies in Brazilian health? v) Do you know any Brazilian public health policy support for sexual diversity? Tell me a little. vi) In your opinion what are the duties of a health service and health professionals? vii) You demand for health services often? What are the main reasons for the search? viii) How is access to health services? Tell me about it. ix) Have you ever reveal or disclose their sexual orientation when looking for health services? Because? x) Have you suffered any constraint or violence by health professionals in health services? Tell me what happened. xi) And otherwise? Tell me if there is a report of a service without violence. xii) Do you believe that health services have been able to meet the health needs of LGBT people? Why do you think that? xiii) How do you perceive the health professionals role in serving the LGBT population? Because? xiv) What do you think is needed for services and health professionals meet their health needs? $\mathrm{xv}$ ) Would you like to add something to your interview? Questions about disclosure of sexual orientation during service, institutional violence, dehumanization of assistance and training to care for sexual minorities were the most detailed.

For the interviews were trained interviewers 5, members of the research team. Each interview took an average of 30 minutes and was held at the residence of participants, according to their will and prior appointment. Each interview was conducted in the presence of interviewer and interviewee to reach privacy in providing information.

\subsection{Data Analysis}

Data was organized after listening, transcribing and reading the material. Data were grouped and analyzed, considering the recurrence of ideas, taking into account the assumptions of thematic categorization as proposed by Minayo, which allowed grouping the ideas into categories [20]. With the aim of consolidating the categories of analysis, the interviewees' speeches analysis followed the assumptions of the Theory of Culture Care Diversity and Universality [16].

\subsection{Ethical Considerations}

All participants were informed about the objectives of the study and signed an Informed Consent Form. This research is part of a larger study entitled "Right to health: implications of homosexuality as a challenge to public health policies and access to services”, submitted and approved under register number: 11771612.8.0000.0082.

\section{Results}

\section{Characteristics of Participants}

Thirty LGBT participated in the research, with predominant sexual orientation of gays $(70 \%, \mathrm{n}=21)$, followed by lesbians $(20 \%, n=6)$ and bisexuals $(10 \%, n=3)$. From the total of gays, $30 \%(n=9)$ were transvestites. From the 30 participants, $80 \%(n=24)$ had male biological sex, with $53.3 \%(n=16)$ presenting also male gender identity.

The most prevalent age group was 38 to 42 years old $(36.6 \%, n=11)$. In relation to ethnicity, participants were predominantly brown $(40 \%, \mathrm{n}=12)$. When asked about their marital status, most of them $(73.3 \%, \mathrm{n}=22)$ reported not being in a loving relationship, although four subjects (13.3\%) reported being married. Regarding education, 56.5\% $(n=17)$ reported having more than high school education, although only five $(19.9 \%)$ had completed higher education. Most of them $(80 \%, \mathrm{n}=24)$ reported engaging in some paid work. It is worth noting that three research participants (12.5\%), who declared being transvestites, were sex workers. Considering month income, $45.8 \%(n=11)$ reported receiving approximately $R \$ 1448.00$ and $33.3 \%(n=8)$ received less than $\mathrm{R} \$ 277.52$. Of the respondents, 23.3\% $(\mathrm{n}=7)$ were receiving government federal benefits, especially "Bolsa Família Program” as a supplementary income.

Through the theory concepts, we assessed the lack of integration of health services and the unpreparedness of health professionals concerning the assistance of LGBT population, using the reports of the study participants and the selected thematic categories. 


\section{“You were born as a man”: male feminization as a trait of inferiority}

The indifference of a big part of the society towards homosexuals is a reality experienced in Brazil, despite the discussions in behalf of the rights of LGBT population. For some studies participants, such indifference is strongly associated with the socially idealized image of a man, as a strong and virile person, which is disqualified in the presence of homosexuality.

Within this framework, two LGBT members revealed to have been victims of prejudice and targets of jokes and derogatory attitudes by health professionals. The institutional violence sustained by them seems to be the result of rejecting the typically female attitudes and behavior practiced by some homosexuals. Discrimination was considered an obstacle to access to health services. The situation points out to the noncompliance of the right to LGBT members to health care, as stated by the Book of Rights of SUS Users, Article 3, which shows that every Brazilian citizen is entitled to a warm care in the health services network in a humane way, free from discrimination, restriction or denial on the basis of age, race, color, ethnicity, sexual orientation, gender identity, genetic characteristics and economic and social conditions [21].

Because, for example, the gay who is more masculine is more likely to pass unnoticed (...) but the effeminate gay suffers a lot, he is the target of jokes, prejudice (...) then, for these issues, many stop using health services. Gay, 27 years old.

When I was there in the operating room, I think because of the medication, I started raving (...) I remember I said just like this, "I was born gay" then I remember a male professional said "you were born man!" I found this an insult by this healthcare professional. Gay, 39 years old.

Besides embarrassment due to homophobic attitudes in services, LGBT members reported receiving disrespectful treatment during assistance. One respondent pointed out the lack of recognition of her sexual orientation by the healthcare professional and the imposition of heteronormative treatment, which reaffirms the biological sex of the individual, disrespecting their uniqueness and gender identity.

They (health professionals) are bothered to treat me like "she" (...). Sometimes they try not to say it (...) I do not allow him to call me "he” (...). "Do you see a man here?". Tranvestite, 37 years old.

"I do not need to reveal my sexual orientation, because they never ask": heteronormative behaviors in professional's everyday practice.

When talking about the right to health, we consider not only the need for physical availability of health services, but also access to cultural and organizational issues related to care. In this context, the worldview of health professionals, according to the perception of the LGBT population, reveals the hegemonic thought of “universal heteronormativity” that guides the health professionals' behavior, reaffirming that this behaviors are just reflections of the socio-cultural values imposed by a heterosexual society.

Given this condition, two LGBT members noted that the invisibility of their sexual orientation during health care is a problem, since the conduct of health professionals presumes heterosexuality of all patients. Thus, since they are not asked about their sexual orientation and gender identity, they do not reveal them.

I've done several consultations without revealing my sexual orientation, because they have never asked me. Gay, 27 years old.

If you ask me and whether I am married, I am! Yes, but it is rare to be asked with whom. Lesbian, 39 years old.

Another participant of the study revealed that health professionals only ask about her sexual orientation when she goes to hemotherapy centers to donate blood (for example, Hemotherapy Centre of Ceara-HEMOCE), as a prerequisite to release or not the procedure. According to her testimony, the questioning on sexual orientation is not performed when LGBT individuals demand for care in other health services.

When I go to the consultation, unless it is in the HEMOCE to donate blood or not, I do not need to reveal my sexual orientation, because they never ask. Lesbian, 22 years old.

"Be careful, he is 'fagot": the dehumanization of health care in the Lesbian, Gay, Bisexual, and Transgendered group

At this topic, we will discuss the need of humanizing care, assistance and the relationship with the user of health services. The extensive discussions regarding this concept guided the elaboration of the National Policy for Humanization of the Brazilian Health System, the Unified Health System [21].

When this condition is not fulfilled, the impasse and the dehumanization of care are evident, as indicated by the respondents, when emphasizing the objectification of the health service user, the position of power of the health professional and the imposition of the biomedical model of care. In addition to this, the situations of ex- 
plicit violence against the LGBT group illustrate the homophobia they have experienced.

In this sense, a LGBT member revealed to have suffered embarrassment when he needed access the health service as a result of blood loss in one of the upper limbs, and to have been target of hurtful words that associate homosexuality with HIV. Although it is known that the transmission of the virus can occur through contact with blood, regardless of sexual orientation of the patient, the inevitable association between homosexuality and sexually transmitted diseases like AIDS still seems to prevail in the minds of some health professionals. This association implies homophobic and exclusionary conduct in the provision of health care to LGBT members.

I arrived at the health center, then everyone gets away from me because I am gay, everyone is afraid of me (...) and people think I have AIDS (...) One day I was taken to the hospital with my arm bleeding and when I got there, the first thing I heard was the nurse screaming "be careful, he is fagot" (...) they cannot touch me because I'm gay? Gay, 40 years old.

Another participant pointed out to have experienced deficient relationship to health professionals, revealing that when sexual minorities search the services, they suffer indifference and exclusion by professionals, materialized in discriminatory looks and difficulties to receive attending.

Because when we go to some health center, they hardly want to receive us. They look at you in a different way and even ask what you are doing there. The duty of the health professional is to attend, to take and to care for you. Transvestite, 38 years old.

I saw once when a gynecologist refused to do a prevention test in a lesbian, because the lesbian was too masculine, the doctor was afraid to go in the room with her (...) because there are professionals who are not prepared to care for LGBT. Yes, there are. Gay, 41 years old.

"Why do they not attend me soon?": the homosexual orientation as an obstacle to equality of care

The creation of Unified Health System meant a fundamental step to equity and to universal health care access. The Unified Health System has legitimated the right to health as a right to citizenship, and set as the State's duty to provide the necessary resources for achieving such prerogative.

However, the population that participated in the study revealed that there are deficiencies in guaranteeing the right to health, pointing obstacles to access to services. It is known that although health services associated with SUS have improved over the decades, funding, infrastructure and human resources restrictions [22] interfere with the provision of services to users. However, despite this condition is extended to the entire population, it seems that the LGBT group has greater difficulty to access to services.

This is stated by LGBT members to denounce that before knowledge of patients' homosexual orientation, the care provided by health professionals is discriminatory. The following lines evidence the discrimination that occurs when patients are selected to be immediately attended and the delay in serving those with homosexual and bisexual orientation.

For example, a nurse (...) sees that there is a transvestite, a gay or a lesbian coming into that unit and cannot say: No, no! So-and-so, you serve this person, if another person arrives, I serve the other person, and you serve now, right? Gay, 42 years old.

I've been through this. I got sick in hospitals, I said I was sick, then instead of being served before others, I had to keep waiting, waiting, and time was passing and it bothered me (...) They do not even pretend they care (...) I think it was because of prejudice, they did not care, they were not moved by that (...) Why did not they serve me sooner? It is not because they cannot, since for others they could do it. Transsexual, 25 years old.

Another participant said that medical professionals usually provide an unsatisfactory care for all patients. However, if health workers come to know about the homosexuality of a user, they will postpone care, which increases the vulnerability of sexual minorities to health hazards.

And despite everything, when you arrive at these hospitals, especially public ones, and you show that you are (homosexual), you will wait longer, you will not get immediate care, and people will not care about you (...) If you go to the doctor, most of them do not even look at the patients who are heterosexual and when they find out that the patient is homosexual, they leaves us there, sitting alone. They do not know how to treat people, they are doctors of ignorance. So, this is the routine. Gay, 40 years old.

\section{Discussion}

Currently, questions related to the health of LGBT group became targets of debate and discussion. In addition to epidemiological and biomedical information on the prevalence of diseases, risk and vulnerability of this popula- 
tion, it is necessary to obtain information about the formulation of public health policies for this group, the structure of health services, training and behavior of professionals in meeting their needs, as these are factors that interfere directly in the access and to guarantee the right to health for sexual minorities [11] [23].

In this sense, it is known that the relationship between users and health professionals is considered essential to strengthen the quality of care and adherence of therapeutic proposals by users. However, the LGBT population, despite advances in legislation, still suffers from unpreparedness of health professionals in meeting their needs, which end up being repressed [8] [24].

This is one of the conclusions of our study, in identifying the perception of LGBT members about the care received by health services, based on the Cross-Cultural Theory. The results expressed the presence of prejudice and discrimination in the conduct of health professionals, invisibility of bisexuals and homosexuals, dehumanization of care, lack of care, isolation and exclusion.

Analyzing the assistance to LGBT group in the light of cross-cultural theory, it is noted the presence of a heteronormative culture in which gender relations seem to permeate the social and moral values [25], serving as support for development of laws and defining roles for each biological sex. When such papers are rejected or are not followed, as the example of homosexuality and bisexuality, rejection behaviors are glimpsed in a vicious circle, passed on through generations.

Thus, the worldview affects the valuation of heteronormativity, strengthening in individuals value references, such as heterosexuality, giving them the name of normality and morality, and the opposite of that condition (homosexuality and bisexuality) is considered as something amoral and abnormal [26]. This world view is embodied in the environmental context. In this sense, biased attitudes and discrimination arise when heteronormativity supporters are faced with members that support and experience the sexual diversity [4].

It is in this scenario that the concepts of care and health fit. It is in the midst of a heteronormative cultural context, a worldview that associates homosexuality and bisexuality to lack of morality and biased environmental context, that health professionals are molded and subsequently released to the labor market to assist the population, including the LGBT.

Thus, considering its cultural aspects, care has deficiencies, since LGBT group has not received the proper attention from health professionals, which has implications to health as a complete state of well-being. In this sense, the cultural and contextual influences shape the trajectories of care [27].

This reality can be illustrated by an adaptation of the sunrise model, i.e., through a cognitive map that didactically explains the interdependence of the concepts inherent to the theory, adapted to homosexuality and its relationship with health (Figure 1).

Recognizing the complexity of the five concepts inherent to Transcultural Theory, adapted to care practices aimed at LGBT group, stereotypes produced in this population harm personalized service and cultural practices end up reinforcing discrimination messages [17].

This scenario seems to be a result of the culture in which health professionals are inserted. They adopt a hegemonic idea, present in the social imaginary, that sexuality should be heterosexual, and that accepting the opposite can mean going against something considered natural [28].

It is noteworthy that, historically, homosexual behavior was not considered abnormal in various civilizations, since age differences existed, and homosexuality had as its purpose the transmission of knowledge, as the example of ancient Greece, with the paradigm of male education, Paideia [29].

Sex between men of the same age was considered unnatural because it meant that one of the men adopted the passive position, betraying thus masculinity that was required for them to perform the role of active citizen. At no time man could lose the condition of dominant "male", not to be compared to women and their consequent fragile image [29]. This cultural representation seems to have been passed on from generation to generation and this worldview has contributed to the social barriers of acceptance of the homosexual population in society.

In agreement with this prerogative, it can be seen in the participants' speeches that the root of the current conflicts seems to be associated with the gradual process of feminization of homosexuals. The act of assuming female characteristics means, for the individual, being exposed to a repressive environment. Their gestures, their posture, the way they dress up, the form and the expression of their faces, their anatomy, and the female morphology of whole body are regularly part of a disqualifying description.

As a result of this situation, the symbolic violence suffered in health institutions is characterized by jeers and prejudice as a result to effeminate mannerisms adopted by homosexuals (gays, transvestites and transsexuals). Discriminatory attitudes arise in society as a response to behaviors that must be fought against, for the benefit of a 


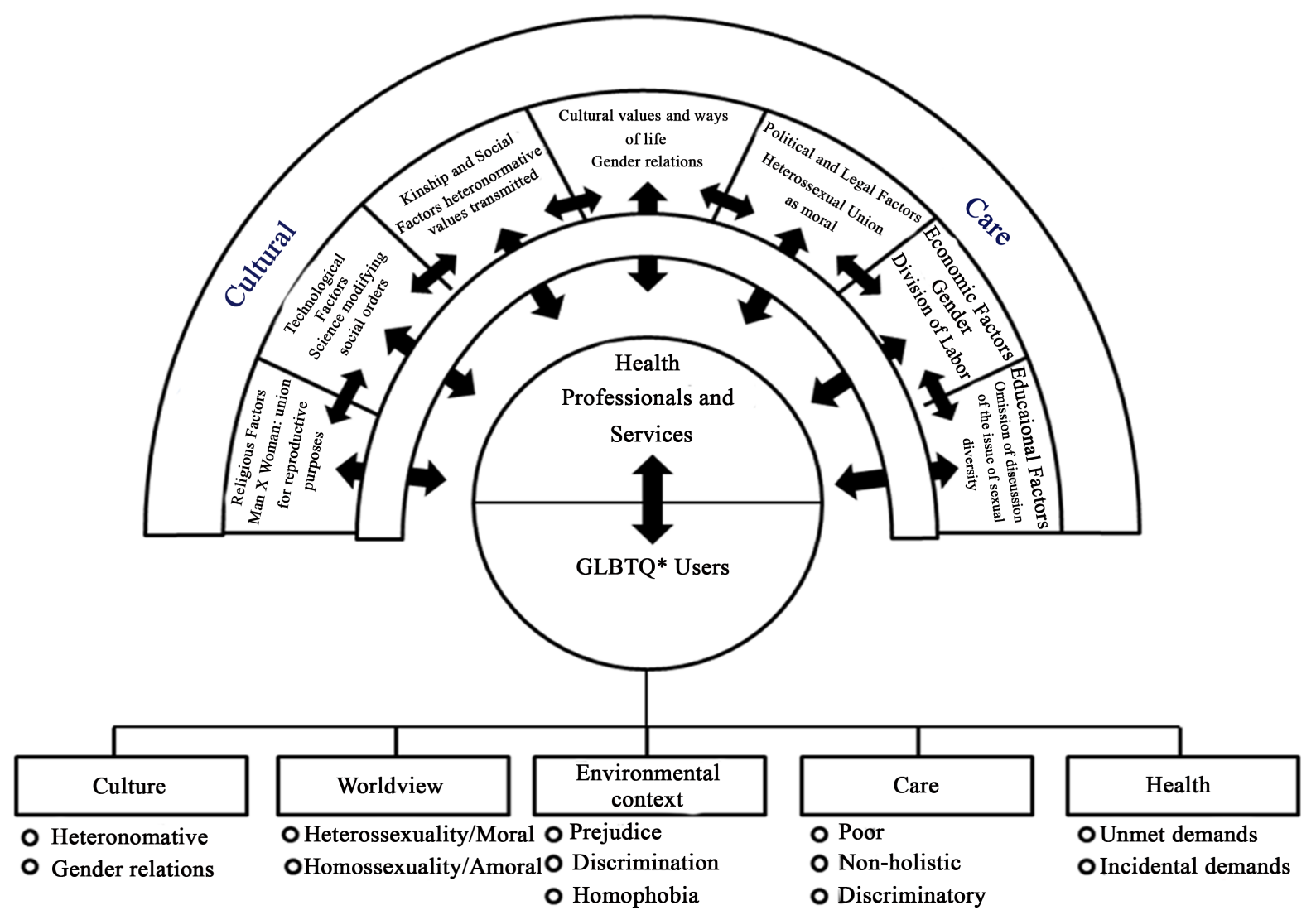

Figure 1. Adaptation of the sunrise model. Association between the political, educational, economic, religious, cultural beliefs and values that influence the health care of Lesbian, Gay, Bisexual and Transgendered (LGBT) group. Source: Adaptation of Sunrise Model (Leininger, 1998).

legitimate masculinity [30]. Being a man is synonymous with virility and strength, and feminization is unacceptable.

In this context, gender relations, which are cultural, when influence the notion of roles and functions of men and women, show that social institutions are organized and crossed by assumptions of what being male and female means, that is, by gendered relationships. The presumed and socioculturally propagated heterosexuality as a result of these relationships appears as a standard imposed by society and taken by individuals as a reflection and synonym of normality. Consequently, everything that escapes from this worldview is regarded as abnormal or even disease [31].

In fact, the speeches of LGBT members point out that the stance adopted by health professionals during the consultations reinforces a presumed and universal heterosexuality for all patients, which may hinder professionals to meet the needs regarding the specificities of other forms of sexual orientation [4]. On the other hand, the LGBT population, when not questioned, can be introverted about their sexual orientation, preventing dialogue and elimination of questions that could be shared with the professional, whether by shyness or fear of social discrimination [4].

Studies indicate that homophobia and heterosexism are barriers that prevent homosexuals from feeling comfortable with their sexual orientation, and from expressing it without problems.

Research shows that $89 \%$ of individuals working in health services manifest negative reactions when a person identifies him/herself as gay or lesbian [32]. Given this reality, many homosexuals, while accepting their sexuality, choose not to publicly reveal it, due to the need for security, and to the dominant fear of retaliation and rejection [4] [33].

Thus, according adaptation of Transcultural Theory, it is observed that there are gaps in health care regarding the LGBT population, given the cultural context in which professionals are inserted. Often, in health services, it is adopted a completely fictitious service, since the presumed heterosexuality in association with the fear of dis- 
crimination by the LGBT population prevents the disclosure of homosexual and bisexual orientation [8] [9].

Consequently, this group is treated as heterosexual and reveals their dissatisfaction with the service received, which, in part, does not address their real needs and desires [8]. In exceptional cases, such as blood donation, there are protocols to be followed by health professionals during screening, which often require explanation of sexual behaviors and sexual routines.

Concerning blood donation, questioning the sexual orientation is considered a priority to determine the "donor" condition. Although the Ministerial Decree 1353 of June 13, 2011, have approved the technical regulation of hemotherapy procedures, in its Article 1, Section 5, it claims that sexual orientation (heterosexuality, bisexuality and homosexuality) should not be used as a criteria for selection of blood donors, because this is not a risky condition in itself [34]. Many hemotherapy centers in the country, as the Hematology Center of Ceara (HEMOCE), still do not accept blood donations from gays, with the justification that they are promiscuous [33] and have higher chances of contracting HIV/AIDS.

In this context, the inevitable cultural association between AIDS and homosexuality, which I still present in the health professionals' imaginary, impacts on the negative and arbitrary judgment towards LGBT population. According to Terto Jr., the worldview on homosexuals brings a stigma from the following association: AIDShomosexuality-promiscuity [35], which implies acute vulnerability of this group in relation to HIV [36]. If, on the one hand homosexuals are blamed for spreading the virus, on the other hand this association moves them away from health services as a result of prejudice and discrimination perpetrated by professionals, which certainly influences the reduction of self-care and the search for preventive health information, increasing their susceptibility to virus infection.

However, whether or not a person is HIV-positive, based on the principle of universality of assistance of SUS, the health service must ensure universal access to all people, and should absorb users of all social strata, consolidating itself as a space that equally meets health needs and that reaffirms the democratic principles of its institution [37].

Apart from the prejudiced HIV-homosexuality association, observed in the speeches, LGBT members experience their embarrassing situations when attended by health professionals, which covers from the lack of respect by using embarrassing and hurtful words to the invisibility of LGBT, from the avoidance of professional/user eye contact to the screening process used to select the next patient, to the exclusion and to the postponement of healthcare. Undoubtedly, such attitudes, considered inhuman and unethical, reflect the prejudice and discrimination against the group, in complete disagreement with the principles of care humanization.

The proposal of National Policy for Humanization is in agreement with the principles of Unified Health System, emphasizing the need to ensure comprehensive care and equity to the population and strategies to expand the condition of citizenship and rights of people [38]. In this perspective, the Unified Health System, through the Book of Rights of SUS Users (675/GM Ordinance, the Official Gazette of March 31, 2006) [21], took a step forward to ensure humanized care to all citizens, free from prejudice and discrimination, based on sexual orientation and gender identity, including ensuring the use of the social name for transvestites and transsexuals, in order to promote access to health care [23]. However, difficulties in the consolidation of this right in the practice of healthcare professionals were reported, as revealed by one of the interviewees, transvestite, 37, in which "they are so bothered in treating me like her, with the pronoun, as it is said, with her."

Still, situations of rejection are commonly manifested through direct refuse to serve the homosexual user, as seen in the expression "So-and-so, you serve this person, if another person arrives, I serve the other person", and also through hostility perpetrated by health professionals, as in "they do not even pretend they care", or through abandonment, "they leaves us there, sitting alone."

In general, the cultural practices that permeate the professional attitudes in caring for LGBT members result in barriers to the achievement of the doctrinal principles of the SUS. When analyzing the junction of the five elements inherent in Transcultural Theory and their applicability to health practices for the LGBT group it is noticed that there is a violation of the rights of the Brazilian health system users by hindering their access to health services. This access should occur in an organized, humanized and respectful way, free of any discrimination, and meeting the demands on health services in a fair and resolute way, as recommended by guidelines of the Book of Rights of the SUS Users [21].

The violation of the principles inherent in the Book result in barriers to achieving the doctrine of SUS towards the LGBT group, since they will not receive a universal access and prejudice-free (universality), fair and resolute (equity), humanized and holistic (comprehensiveness) service [21] (Figure 2). 


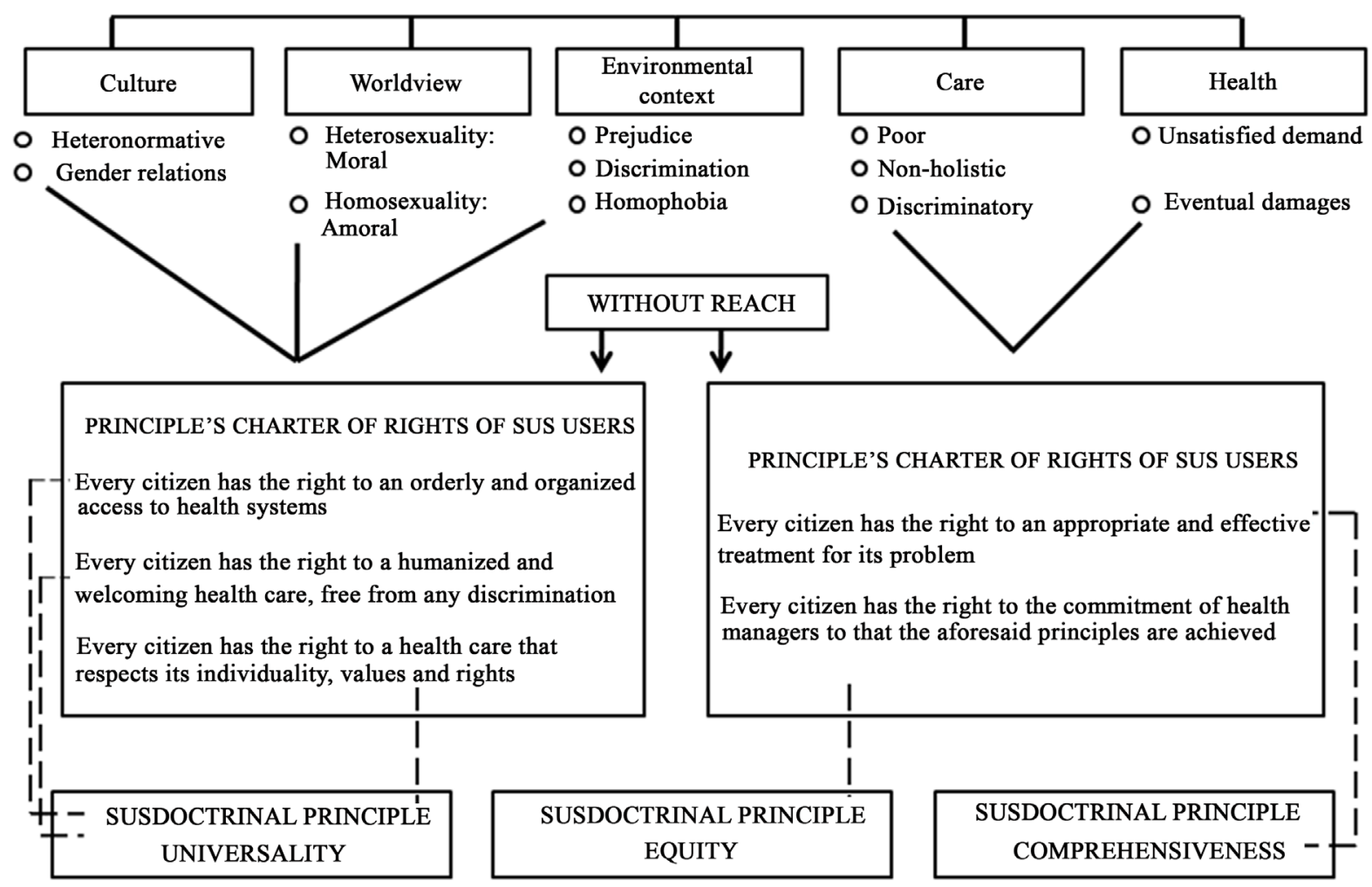

Figure 2. Implications of the concept of cross-cultural theory adapted to the care practices directed to the LGBT group in achieving the doctrinal principles of the Brazilian Health System.

Thus, there is the need to provide, in professional education in health, information concerning the operation of SUS, and also data on gender relations, sexual diversity and healthcare to the LGBT population, focusing on standards of communication, on understanding the relationship between health, disease, and sexual orientation, on knowledge of the cultural issues surrounding this group and in addressing the most common health problems that affect this population [39].

Health institutions, as knowledge production locus and genesis of training new health professionals, should discuss issues related to homosexuality and bisexuality, taking into account culture, worldview and the environmental context in which these professionals are inserted, since these factors, as Leininger [16] states, influence in the provision of care, i.e., in culturally appropriate health care, which pre-requisite for achieving the doctrinal principles of the SUS.

The discussion of this subject in the curricula provokes debates inherent sociocultural constructions of a society, as a starting point for the analysis of social determinants of health and the effective intervention on them, such as the discussion on the relationship between sexual diversity and health services. Indeed, all universities and other educational institutions have been pressured by changes in the professional training process and in the way the university relates to society [40]. In this context, university should be the foundation for the occurrence of social changes that lead community to reach their citizenship rights.

\section{Conclusions}

The discussion of this theme in the light of Leininger's Transcultural Theory seems to point and justify the reasons for the difficulties encountered in health professionals practice to provide assistance to the LGBT population in accordance with the doctrine of SUS. The adoption of a heteronormative culture, a worldview that rejects homosexuality and a prejudiced environmental context provide misconduct of health professionals.

Thus, it is necessary to ensure, in addition to the provision of health services to meet these clients' needs, that health professionals are trained and qualified to effectively step into the issues surrounding sexuality and free sexual orientation, free of heteronormative cultures and discriminatory attitudes, and that they are able to ana- 
lyze the health status of their customers and the social determinants of health that may affect them and cause injuries.

It is recommended therefore, introducing and discussing these topics in health professional undergraduate curricula is important, as this will contribute to social and cultural construction. Besides, it is also crucial to conduct training to those who are already working in the area, to monitor the implementation of laws against homophobia, and the development of front empowerment strategies to LGBT population, so that they can act in the endless search for achievement of their rights, leaving the invisibility and becoming visible as a subject in their history.

Still, it points out the need to carry out further research on the subject to discuss, from the perspective of the LGBT population, the need to implement a health policy focused on sexual diversity in health services, as well as discuss the practices of health (in) exist to meet the health needs of this population from health professionals, helping to demystify the prejudice and social exclusion that pervade the reality of this population.

\section{Limitations}

Some limitations of the study can be identified. Due to its qualitative feature, it does not allow generalization of the results, although the uniform presence of speeches may raise the future exploration of the data. Events may not have happened as reported, since some are not recent memories. Although such limitations are present, we are confident that the experiences of dissatisfaction of the LGBT population during health care services are real, in view of the cultural base of the professionals of the area. We point, as a reason for the credibility of the data, the saturation process obtained when the speeches of the participants began to become repetitive, revealing the uniformity of life experiences, which took place with 30 participants, a higher number when compared to other qualitative studies.

\section{References}

[1] Cardoso, M.R. and Ferro, L.F. (2012) Health and LGBT Population: Demands and Specificities in Question. Psicologia: Ciência e Profissão, 32, 552-563. http://www.scielo.br/pdf/pcp/v32n3/v32n3a03.pdf

[2] Mello, L., Perilo, M., Braz, C.A. and Pedrosa, C. (2011) Health Policies for Lesbians, Gays, Bisexuals, Transvestites and Transsexuals in Brazil: In Search of Universality, Comprehensiveness and Equity. Revista Latinoamericana Sexualidad, Salud y Sociedad, 9, 7-28. http://www.scielo.br/pdf/sess/n9/02.pdf

[3] Moscheta, M.S. and Santos, M.A. (2010) Inclusion and the Challenge of Creating Forms of Collaborative ResearchOne Experience Report. Saúde \& Transformação Social, 1, 154-159. http://incubadora.periodicos.ufsc.br/index.php/saudeetransformacao/article/view/415/447

[4] Neville, S. and Henrickson, M. (2006) Perceptions of Lesbian, Gay and Bisexual People of Primary Healthcare Services. Journal of Advance Nursing, 55, 407-415.

http://www.hivlawandpolicy.org/sites/www.hivlawandpolicy.org/files/perceptions\%20of\%20LGBT\%20of\%20healthca re\%20providers.pdf http://dx.doi.org/10.1111/j.1365-2648.2006.03944.x

[5] Buddel, N. (2011) Queering the Workplace. Journal of Gay \& Lesbian Social Services, 23, 131-146. http://dx.doi.org/10.1080/10538720.2010.530176

[6] Zanardo, B.V.S. and Andrade, S.M.O. (2013) Reflections on Sexual Diversity in Health Care: A Literature Review. Revista Pitágoras, 4, 1-12. http://www.finan.com.br/pitagoras/downloads/numero4/reflexoes-sobre-as.pdf

[7] Kalfoss, M. (2016) Gender Differences in Attitudes to Ageing among Norwegian Older Adults. Open Journal of Nursing, 6, 255-266. http://dx.doi.org/10.4236/ojn.2016.63026

[8] Kerker, B.D., Mostashari, F. and Thorpe, L. (2006) Health Care Access and Utilization among Women Who Have Sex with Women: Sexual Behavior and Identity. Journal of Urban Health, 83, 970-979.

http://www.ncbi.nlm.nih.gov/pmc/articles/PMC2438586/ http://dx.doi.org/10.1007/s11524-006-9096-8

[9] Araújo, M.A.L., Saraiva, M.M.M., Galvão, M.T.G. and Albuquerque, A.D. (2006) The Health Professional-User Relationship: Experience of a Homosexual Woman in a Renowned Fortaleza Health Unit. Escola Anna Nery Revista de Enfermagem, 10, 323-327. http://www.scielo.br/scielo.php?pid=S1414-81452006000200022\&script=sci_arttext http://dx.doi.org/10.1590/S1414-81452006000200022

[10] Gutiérrez, N.I.M. (2007) Homosexual Situation of Sexual and Reproductive Health, Homosexual Men and Women, Hospital María Auxiliadora. Revista Peruana de Obstetricia y Enfermería, 3, 2-16. 
http://revistas.concytec.gob.pe/pdf/rpoe/v3n1/a02v3n1.pdf

[11] Heck, J., Randall, V. and Gorin, S.S. (2006) Health Care Access among Individuals Involved in Same-Sex Relationships. American Journal of Public Health, 96, 1111-1118. http://www.ncbi.nlm.nih.gov/pmc/articles/PMC1470619/ http://dx.doi.org/10.2105/AJPH.2005.062661

[12] Moura, M.A.V., Chamilco, R.A.S.I. and Silva, L.R. (2005) Transcultural Theory and Its Application in Some Research of Nursing: A Reflection. Escola Anna Nery Revista Enfermagem, 9, 434-440. http://dx.doi.org/10.1590/S1414-81452005000300012

[13] Buss, P.M. and Pellegrini Filho, A. (2007) Health and Its Social Determinants. Physis: Revista de Saúde Coletiva, 17, 77-93. http://www.scielo.br/pdf/physis/v17n1/v17n1a06.pdf http://dx.doi.org/10.1590/S0103-73312007000100006

[14] Budó, M.L.D.R. and Saupe, R. (2005) Ways of Care in Rural Communities: Culture Permeating the Nursing Care. Texto \& Contexto-Enfermagem, 14, 177-185. http://dx.doi.org/10.1590/S0104-07072005000200004

[15] Leininger, M. (1998) Ethnography and Ethnonursing: Models and Modes of Qualitative Data Analysis. In: Leininger, M., Ed., Qualitative Research Methods in Nursing, Grune \& Stratton, Orlando, 33-72.

[16] Leininger, M. (2001) Towards Conceptualization of Transcultural Health Care Systems: Concepts and a Model. In: Leininger, M., Ed., Culture Care Diversity and Universality: A Theory of Nursing, National League for Nursing Press. New York.

[17] McCrae, N. and Mayer, F. (2014) The Role of Nurses in Tackling Female Genital Mutilation. International Journal of Nursing Studies, 51, 829-832. http://www.journalofnursingstudies.com/article/S0020-7489(13)00218-6/fulltext http://dx.doi.org/10.1016/j.ijnurstu.2013.07.004

[18] Godoy, A.C. (1995) Qualitative Research: Fundamental Types. Journal of Business Administration, 35, $20-29$. http://www.scielo.br/pdf/rae/v35n3/a04v35n3.pdf

[19] Albuquerque, E.M. (2009) Sampling Technique of Evaluation "Respondent-Driven Sampling" in the Estimation of Communicable Disease Prevalence in Populations Organized in Complex Networks. Master Dissertation, Ministério da Saúde/Escola Nacional de Saúde Pública/Fiocruz, Rio de Janeiro, 99 p. http://bvssp.icict.fiocruz.br/pdf/Albuquerqueemm.pdf

[20] Minayo, M.C.O. (2004) Challenge of Knowledge: Qualitative Health Research. Hucitec, São Paulo.

[21] Brazil, M.S. (2006) Ordinance No. 675/GM of 30 March 2006. Charter of Rights of the Health Users, Ministério da Saúde, Brasília. http://dtr2001.saude.gov.br/sas/PORTARIAS/Port2006/GM/GM-675.htm

[22] Paim, J., Travassos, C., Almeida, C., Bahia, L. and Macinko, J. (2011) The Brazilian Health System: History, Advances and Challenges. The Lancet, Séries Saúde no Brasil, 377, 1778-1797. http://dx.doi.org/10.1016/s0140-6736(11)60054-8

[23] Lionço, T. (2008) That the Right to Health for the LGBT Population? Considering Human, Sexual and Reproductive Rights in Pursuit of Comprehensiveness and Equity. Saúde e Sociedade, 17, 11-21. http://dx.doi.org/10.1590/S0104-12902008000200003

[24] Hiestand, K.R., Horne, S.G. and Levitt, H.M. (2007) Effects of Gender Identity on Experiences of Healthcare for Sexual Minority Women. Journal of LGBT Health Research, 3, 15-27. http://dx.doi.org/10.1080/15574090802263405

[25] Matharu, K., Kravitz, R.L., McMahon, G.T., Wilson, M.D. and Fitzgerald, F.T. (2012) Medical Students’ Attitudes toward Gay Men. BMC Medical Education, 12, 71. http://www.biomedcentral.com/1472-6920/12/71 http://dx.doi.org/10.1186/1472-6920-12-71

[26] Carvalho, L.S. and Philippi, M.M. (2013) Perception of Lesbians, Gays and Bisexuals in Relation to Health Services. Universitas: Ciências da Saúde, 11, 83-92.

[27] Evans, C.B., Crogan, N., Beleya, M. and Coon, D. (2009) Utility of the Life Course Perspective in Research with Mexican American Caregivers of Older Adults. Journal of Transcultural Nursing, 20, 5-14. http://www.ncbi.nlm.nih.gov/pmc/articles/PMC3750709/ http://dx.doi.org/10.1177/1043659608325847

[28] Barbosa, R.M. and Fachinni, R. (2009) Access to Care Related to Sexual Health among Women Who Have Sex with Women in São Paulo, Brazil. Cadernos de Saúde Pública, 25, 291-300. http://dx.doi.org/10.1590/S0102-311X2009001400011

[29] Corino, L.C.P. (2006) Homoerostismo in Ancient Greece-Homosexuality and Bisexuality, Myths and Truths. Biblos, 19, 19-24. http://www.brapci.inf.br/_repositorio/2010/06/pdf_7b61bc03a1_0010976.pdf

[30] Lopes, C.R.R. (2011) Masculinity in Rose: Effeminate Gay/Discrete Men. MÉTIS: História \& Cultura, 10, 165-184. http://www.ucs.br/etc/revistas/index.php/metis/article/viewFile/989/1070 
[31] González, M.L.L.S. and Licona, N.E.A. (2006) Normalization of Homophobic Speech: Bioethical Aspects. Actha Bioethica, 12, 211-217. http://dx.doi.org/10.4067/S1726-569X2006000200010

[32] Brotman, S., Jalbert, Y., Rowe, B. and Ryan, B. (2002) The Impact of Coming out on Health and Health Care Access: The Experiences of Gay, Lesbian, Bisexual and Two-Spirit People. Journal of Health \& Social Policy, 15, 1-29. http://dx.doi.org/10.1300/J045v15n01 01

[33] Venancio, J.C. (2010) Homophobia and Consequences of Not Assumption of Homosexuality: A Study on LGBT Vision. Master Dissertation, Faculdade de Psicologia e de Ciências da Educação da Universidade do Porto, Porto, 67 p. https://www.rea.pt/imgs/uploads/doc-estudos-homofobia-consequencias-(nao)-assumpcao-homossexualidade-um-estud o-sobre-visao-LGBT.pdf

[34] Brazil, M.S. (2011) Ordinance No. 1353 of 13 June 2011. Approves the Technical Regulation Haemotherapic Procedures. Ministério da Saúde, Brasilia. http://portal.anvisa.gov.br/wps/wcm/connect/7a2915004b948667a9fabbaf8fded4db/Portaria_MS_1353_13_de_junho_ de_2011.pdf?MOD=AJPERES

[35] Terto Jr., V. (2002) Homosexuality and Health: Challenges for the Third Decade of the HIV/AIDS. Horizontes Antroplógicos, 8, 147-158.

[36] Peel, E. (2010) Abortion in Lesbian and Bisexual Women: An Online Search Experience. Human Reproduction, 25, 721-727. http://dx.doi.org/10.1093/humrep/dep441

[37] Santos, T.V.C. and Penna, C.M.M. (2013) Daily Demands in Primary Care: A Vision of Health Professionals and Users. Texto \& Contexto-Enfermagem, 22, 149-156.

http://www.scielo.br/scielo.php?script=sci_arttext\&pid=S0104-07072013000100018 http://dx.doi.org/10.1590/S0104-07072013000100018

[38] Santos-Filho, B.S. (2007) Assessment of Prospects in the National Humanization Policy in Health: Conceptual and Methodological Aspects. Ciência \& Saúde Coletiva, 12, 999-1010. http://dx.doi.org/10.1590/S1413-81232007000400021

[39] Mcnair, R.P. and Hegarty, K. (2010) Guidelines for the Primary Care of Lesbian, Gay, and Bisexual People: A Systematic Review. Annals of Family Medicine, 8, 533-541. http://www.ncbi.nlm.nih.gov/pmc/articles/PMC2975689/ http://dx.doi.org/10.1370/afm.1173

[40] Ceccim, R.B. and Feuerwerker, L.C.M. (2004) Change Graduation of Health Professions under the Integral Shaft. Cadernos de Saúde Pública, 20, 1400-1410. http://dx.doi.org/10.1590/S0102-311X2004000500036 